\title{
Factors Influencing Teachers' Implementation of a Reformed Instructional Model in China from the Theory of Planned Behavior Perspective: A Multiple Case Study
}

\author{
Wenjun Zhao ${ }^{1}$, Ida Ah Chee Mok ${ }^{2}$ (1) and Yiming Cao ${ }^{3, *}$ \\ 1 School of Mathematical Sciences, Sichuan Normal University, Chengdu 610066, China; \\ zwj6616@mail.bnu.edu.cn \\ 2 Faculty of Education, The University of Hong Kong, HKSAP, China; iacmok@hku.hk \\ 3 International Center for Research in Mathematics Education, Beijing Normal University, \\ Beijing 100875, China \\ * Correspondence: caoym@bnu.edu.cn
}

Received: 15 November 2019; Accepted: 14 December 2019; Published: 18 December 2019

\begin{abstract}
It is difficult for curriculum reform to achieve sustainable success without support from teachers in the front line. The authors of this paper investigated teacher factors behind the successful implementation of a reformed instructional model, the Dao Jiang Ping (DJP) model, in China. This study is part of a longitudinal project (2012-2017) that reported the level of DJP implementation and explored factors that influence teachers' implementation. This paper mainly focuses on the latter. Six teachers were examined to look for reasons behind their different levels of DJP implementation. The theory of planned behavior (TPB), which has been widely used to explain and predict people's behavior or intention to perform a behavior, is used as the theoretical framework for the study. Referring to the TPB framework, this study summarized factors into individual factors, perceived social factors and perceived contextual factors. Furthermore, the authors suggest extending the TPB framework by including teachers' understanding of the reform ideas to facilitate its application in order to explore factors in reform contexts. Lastly, this study discusses several important factors that help teachers to implement new teaching methodologies continually, thus promoting the sustainable implementation of reforms.
\end{abstract}

Keywords: curriculum reform in China; TPB; DJP model; sustainable reform implementation

\section{Introduction}

Many countries have reformed their education practices and released new curriculum standards in the last two decades [1,2]. However, numerous studies show that the sustainable implementation of reform depends on how well the reform ideas are implemented in classrooms by teachers rather than how well they are written in documents (e.g., [3-6]). As Fullan [5] suggests, "implementation is a variable, and if the change is a potential good one, success (such as improved student learning or increased skills on the part of teachers) will depend on the degree and quality of change in actual practice" (p. 70). Nevertheless, research reports that it is challenging to get teachers to implement new ideas, and reforms are not always implemented as expected (e.g., [5,7]).

The current mathematics curriculum reform in China is the eighth and most fundamental one since the founding of the People's Republic of China in 1949 [8]. It began in 2001 when the Curriculum Standards for Mathematics Curriculum of Nine-Year Compulsory Education (Experimental Version) was released [9]. Overall, the current mathematics curriculum reform emphasizes "a change of the 
trend towards over emphasizing knowledge delivery and putting more emphasis on students' active participation to develop their abilities such as collecting and processing new information, gaining new knowledge independently, analyzing and solving problems, and communicating and cooperating with others" [10]. The newest version of the curriculum standard was published in 2011 [11], and the goal of mathematics education was extended from two basics (basic knowledge and skills) to four basics (basic knowledge, skills, mathematical thinking and activity experiences). The standard suggests various instructional approaches to improve students' learning, e.g., self-learning, collaborative learning and inquiry-based learning [11,12]. However, despite the appealing proposals in curriculum reform, research finds that little change is happening in classrooms [13,14]. He and Gao [15], for instance, analyzed 15 middle school mathematics lessons and pointed out that although teachers accepted the reformed model of learner-centered instruction, lecturing still occupied most of their class time. Li [16] found teacher-fronted instruction to be the dominant practice in classes under educational reform, with little interaction between teachers and students. Many Chinese educators call this situation "walk [ing] the old road with new shoes" [12,17].

In recent years, while the implementation of national curriculum reform has moved from centralization to decentralization, with decreased control by the central government and more encouragement for developing local curricula by local educational authorities and communities, successful reform cases have been reported at the local level. The Dao Jiang Ping (DJP) model, a local reform in the LQY district of Chengdu City, Sichuan Province (in Southeast China), has attracted researchers' attention due to its success in changing teachers' classroom practices and promoting students' learning. This instructional model is designed to address the requirements of the national mathematical curriculum reform and meet local needs at the same time and has been promoted in the whole district since 2008 [18]. We posit that the new model is in fact a proposal of revolutionary change and a challenge to traditional teaching practice in China.

This study examines the implementation of the DJP model in Chengdu, China, via a longitudinal project, with a focus on the teacher factors behind its success. There were two phases in the project. Phase 1 reported successful implementation of the model and questioned the pertinent teacher factors behind its success. Phase 2 explored the factors that influence teachers' levels of DJP implementation. This study reports the results of phase 2 . With respect to the choice of theoretical framework, the study used the theory of planned behavior (TPB), which has been widely used in social science studies to predict and explain people's behavior. Studies have examined its effectiveness in exploring the relationship between teachers' behaviors and beliefs [19], explained teachers' reactions to reform [20] and predicted teachers' acceptance of reform [21]. TPB's application in educational reform studies is expanding [22,23]. In a nutshell, the main question of this study is: What are the factors that influence teachers' levels of implementation of the DJP model in China through the lens of TPB?

The United Nations promotes Education for Sustainable Development (ESD) as a global educational goal, which empowers people to change the way they think and work towards a sustainable future. Very often people link ESD to environmental studies. However, according to Cloud [24], education of sustainability suggests some core values in learning, "the habits of mind required for students to actively participate in creating a sustainable future". Hence, we argue that a change in the approach to engaging students in learning should not be limited to sustainability science or environmental studies. It can also have a productive influence on the learning of other disciplines. The DJP model in this paper gives an example of enhancing the three DJP elements (self-study, student teaching attitudes and peer comments), representing a revolutionary change in teacher-student attitudes and behaviors in learning. Hence, the study shows that the reform has demonstrated in the Asian context a successful experience of changing students' attitudes and habits of mind towards learning, and has yielded meaningful effects on teachers' attitudes, which in turn are essential education elements for interdisciplinary sustainable development in the future. 


\section{Literature Review}

\subsection{Factors Influencing Teachers' Implementation of Curriculum Reform}

It is widely agreed that the success and sustainability of curriculum reform implementation relies on the ability of teachers to change their beliefs and teaching practices to align with the reform [6,25]. However, transforming teaching practices is a complex process that is influenced by various factors $[5,26,27]$.

Fullan [5] derived nine factors that influence the implementation of curriculum innovation. They are categorized into three groups: characteristics of change (need, clarity, complexity, quality/practicality), local characteristics (district, community, principal, teacher) and external characteristics (governments and other agencies). Spillane, Reiser and Reimer [28] proposed a "six $\mathrm{P}^{\prime}$ model to explain teachers' various levels of reform implementation. The first $\mathrm{P}$ is the policy sector, including formal district, school and informal policy. The second $\mathrm{P}$ is professional, referring to formal and informal contact between educators and teachers. The third P is pupils. The fourth $\mathrm{P}$ is the public, which includes people in the community, such as parents. The fifth P represents private companies, such as textbook and curriculum publishers. The sixth $\mathrm{P}$ is personal resources, including knowledge, beliefs and dispositions. These models try to broadly cover factors including the reform itself, the context, the educational system and even the society.

With a particular focus on teachers, Thurlings et al. [27] reviewed the literature on factors that influence teachers' innovative behavior and proposed a preliminary model including demographic, individual and organizational factors. Demographic factors include years of education and teaching experience and job functions as a teacher. Individual factors consist of teacher beliefs, attitudes and self-efficacy. Organizational factors refer to colleagues, organizational culture, facilities and resources. Buabeng-Andoh [26] reviewed factors related to teachers' adoption and integration of information and communication technology and placed them into categories: personal factors (e.g., feelings, knowledge and attitudes), institutional factors (e.g., training and facilities) and technological factors (e.g., ease of use, experience and needs).

The reviewed literature shows that the main factors related to teachers' implementation of curriculum reforms can be grouped into individual factors, including teacher beliefs, attitudes and self-efficacy, and contextual factors, such as school culture, training support and resources.

Some researchers claim that individual factors have a more direct influence on teachers' behavior than contextual factors [24,27,29]. Thurlings et al. [27] suggest that "proximal factors, such as traits and motivation, are more closely related to behavior. Distal factors, such as environmental and organizational factors, act from a longer distance to behavior and are mediated by proximal variables" (p. 461). Spillane and Zeuli [29] point out that in the six P model, the sixth P, personal resources (knowledge, beliefs and dispositions), plays a central role. The other five Ps provide support and external resources for teachers to learn about reform and support their changing practice through personal factors.

The authors of this paper agree with the argument that teachers' personal or individual factors have a direct influence on their implementation of reforms, while the contextual factors from their external environment influence their behaviors by changing their beliefs, attitudes and knowledge. Following this perspective, TPB, which has been widely used to explain and predict people's behavior through their beliefs, attitudes, intentions and perceptions of contextual factors, was chosen as the theoretical lens for this study. 


\subsection{Theory of Planned Behavior}

\subsubsection{Theory of Planned Behavior Framework}

The TPB has been widely used in social science to explain and predict people's behavior or intention to perform a behavior in three dimensions: attitude towards the behavior, subjective norms and perceived behavioral control [30,31], as shown in Figure 1.

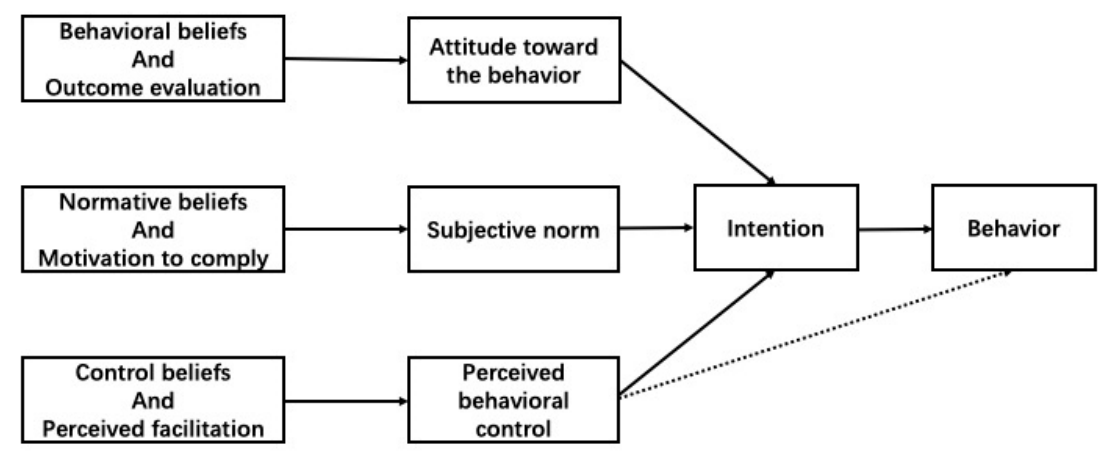

Figure 1. Theory of planned behavior (adopted from [32]).

An attitude is an individual's subjective evaluation of an object that has good/bad, harmful/beneficial and likable/dislikeable attributes. Attitudes are attached to an object when people's beliefs about the object are formed. According to this definition, people's attitudes towards a behavior are determined by their judgement and evaluation of the outcome of performing the behavior [31,32].

Subjective norms are related to social factors and involve the pressure people feel from important others with regard to performing or not performing a behavior. Important others can include parents, teachers, classmates, colleagues and leaders. Different groups of people may have different expectations. A global method for measuring subjective norms is to ask participants to rate the extent of expectation of each individual or group of important others who approve or disapprove of their performance of a behavior [31].

Perceived behavioral control refers to the perceived ease or difficulty of performing a behavior. Ajzen [33] defines perceived behavioral control as two separate components: Perceived self-efficacy and perceived controllability. Perceived self-efficacy refers to an individual's perception of the ease or difficulty of performing a behavior, while controllability refers to the perception of the extent to which performing the behavior depends on him or her. However, although the two components are treated as separate, they are related.

The three dimensions - attitudes towards the behavior, subjective norms and perceived behavioral control-work together to form an individual's intention to perform a behavior. Generally, we can assume that the stronger a person's intention to perform a behavior, the more likely he or she is to carry out the behavior when possible. Thus, intention is regarded as a direct determinant of performing a behavior. However, there are some situations where the individual cannot perform the behavior due to limited resources and time even though he or she may have a high intention to do so. Thus, in addition to intention, perceived behavioral control directly influences behavior.

Furthermore, behavioral beliefs, including perceptions about the outcome of performing the behavior and evaluation of the outcome, form people's attitudes towards behavior. Normative beliefs, including perceptions of the expectations of important others and the motivation to comply with these expectations, determine people's subjective norms. Control beliefs, which determine perceived behavioral control, are inherent factors that support performing the behavior and the perceived power of these beliefs [31-33]. 


\subsubsection{Theory of Planned Behavior Application in Educational Reform Research}

Studies of educational reform from a TPB perspective have tested the effectiveness of TPB in explaining teachers' responses to educational reforms. Several factors have been suggested to influence teachers' implementation of reforms [20,34].

Most of the literature on teachers' reactions to reform shows that their attitudes and perceived behavioral control are strong predictors of their behavior, while subjective norms are a relatively weaker predictor [20,35]. For instance, Pynoo et al. [35] analyzed responses from 919 teachers on their acceptance and use of an educational portal and found that the strongest predictors of behavioral intention were attitudes and perceived usefulness. Alhendal et al. [20] also suggested that attitude and perceived behavioral control are the main predictors of intention and that subjective norms are not a significant predictor.

Relevant studies have also found that although teachers may have positive attitudes, they can fail to implement necessary changes due to contextual factors such as time, resources, materials and a lack of professional development [36].

In addition, students play a key role in influencing teachers' reactions to reform. Sadaf, Newby and Ertmer [37] examined pre-service teachers' intention to use Web 2.0 technologies and suggested that "pre-service teachers were relatively more motivated by the value of this technology to facilitate students' learning and participation and address their future students' expectations regarding the use of web 2.0 technologies" (p. 944). Alhendal et al. [20] pointed out that professional development should provide evidence of students' learning outcomes and help teachers reflect on that learning, as their improvement is a considerable concern for teachers.

However, the application of TPB in educational reform is mainly limited to teachers' acceptance of reform related to information technology services. This study adopts TPB in mathematics education, particularly the mathematical curriculum reform in China, to further explore the possibility that it could be used as a framework for explaining teachers' reactions to reform.

\section{The DJP Model}

\subsection{Basic Procedures of the DJP Model}

Dao Jiang Ping (DJP) is the Pinyin of the Chinese characters 导讲评. These three characters represent the three main elements of the DJP model. "Dao" can be translated as "self-study," which means that with the guidance of learning materials, students explore the learning content before classes. "Jiang" can be translated as "student-teaching," which refers to students teaching their classmates. "Ping" can be translated as "peer-comment," which refers to students making comments on other students' answers. Overall, the DJP model is defined as "a teaching and learning model which aims to develop students' learning ability by the activities of 'self-study,' 'student-teaching' and 'peer-comment,' with guidance from the teacher" [18].

Figure 2 illustrates how self-study, student-teaching and peer-comment constitute the basic structure of the DJP model. Only when teachers integrate and implement the three elements have, they carried out a DJP class [18]. In order to show exactly how students, participate in a DJP classroom, an example from an algebra class is presented in the Appendix A.

\subsection{Comparison among Chinese Traditional Classrooms, DJP Model Classrooms and Student-Centered Classrooms}

This study shows that the DJP model is an instructional model that strives to balance Western-style student-centered instructional approaches (e.g., collaborative, self-regulated and discovery learning) with the traditional features of Chinese mathematics education (e.g., meaningful reception learning, well-structured and coherent instruction, challenging mathematical tasks and heuristic teaching). A comparison of the features of a traditional Chinese mathematics classroom, a DJP classroom and a student-centered classroom is presented in Table 1. 


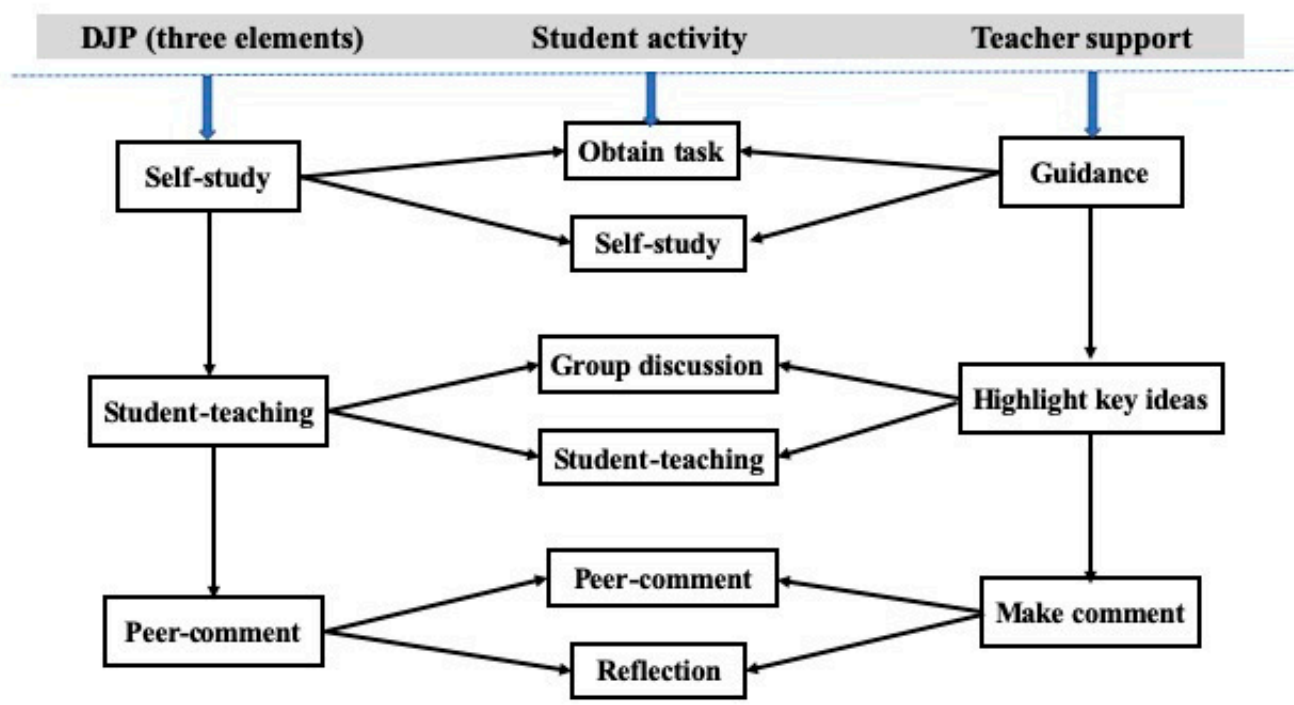

Figure 2. Dao Jiang Ping (DJP) model process (translated from Wang and Wang [18] with authors' permission).

Table 1. Comparison of features of traditional Chinese mathematics classroom, DJP classroom and student-centered classroom.

\begin{tabular}{|c|c|c|c|}
\hline & $\begin{array}{l}\text { Chinese Traditional } \\
\text { Classroom [38-42] }\end{array}$ & DJP Model Classroom [18,43] & $\begin{array}{l}\text { Student-Centered Classroom } \\
\text { (Western Model) [44-46] }\end{array}$ \\
\hline Learning content & $\begin{array}{l}\text { Standardized content } \\
\text { High-cognitive-demand } \\
\text { tasks } \\
\text { Careful task design with } \\
\text { variation }\end{array}$ & $\begin{array}{l}\text { Standardized content } \\
\text { High-cognitive-demand tasks } \\
\text { Careful task design with variation }\end{array}$ & $\begin{array}{l}\text { Diverse tasks depending on } \\
\text { students' different abilities } \\
\text { Learning content linked to } \\
\text { students' lives }\end{array}$ \\
\hline $\begin{array}{l}\text { Roles of teacher and } \\
\text { students }\end{array}$ & $\begin{array}{l}\text { Teacher plays a central } \\
\text { role } \\
\text { Students are cognitively } \\
\text { engaged but do not talk } \\
\text { much }\end{array}$ & $\begin{array}{l}\text { Teacher as guide, facilitator and } \\
\text { co-operator } \\
\text { Students play a central role, acting } \\
\text { as "little teachers" } \\
\text { (student-teaching) }\end{array}$ & $\begin{array}{l}\text { Teacher as facilitator } \\
\text { Students play a central role }\end{array}$ \\
\hline Classroom activities & $\begin{array}{l}\text { Emphasizes teacher's } \\
\text { explanations } \\
\text { Coherent lesson design } \\
\text { Lecturing } \\
\text { Lack of interaction and } \\
\text { collaboration between } \\
\text { students } \\
\text { Lack of exploration } \\
\text { activities }\end{array}$ & $\begin{array}{l}\text { Self-study by students before the } \\
\text { lesson } \\
\text { Students present and explain their } \\
\text { work } \\
\text { Teacher guides, highlights and } \\
\text { enriches students' explanations } \\
\text { Emphasizes student-student } \\
\text { interaction (peer-comment) } \\
\text { Group work and discussion } \\
\text { Active student participation } \\
\text { Coherent lesson design }\end{array}$ & $\begin{array}{l}\text { Self-exploration } \\
\text { Group work } \\
\text { Presentation and } \\
\text { explanation by students } \\
\text { Debate } \\
\text { Active student participation } \\
\text { Communication and } \\
\text { cooperative activities }\end{array}$ \\
\hline $\begin{array}{l}\text { Classroom } \\
\text { interaction }\end{array}$ & $\begin{array}{l}\text { Teacher-whole class } \\
\text { interaction } \\
\text { Teacher-individual } \\
\text { interaction (teacher asks } \\
\text { closed-ended questions } \\
\text { and students provide } \\
\text { short answers, often in } \\
\text { choral responses) }\end{array}$ & $\begin{array}{l}\text { Teacher-whole class interaction } \\
\text { Teacher-individual interaction } \\
\text { Student-student interaction } \\
\text { through group work and peer } \\
\text { comments (both teacher and } \\
\text { students pose questions in class } \\
\text { and students explain their } \\
\text { answers in detail) }\end{array}$ & $\begin{array}{l}\text { Teacher-individual } \\
\text { interaction } \\
\text { Student-student interaction } \\
\text { through group work and } \\
\text { discussion }\end{array}$ \\
\hline Assessment & $\begin{array}{l}\text { Summative assessment } \\
\text { (knowledge acquisition) }\end{array}$ & $\begin{array}{l}\text { Summative assessment } \\
\text { (knowledge acquisition) } \\
\text { Formative assessment (group } \\
\text { work, presentation) }\end{array}$ & $\begin{array}{l}\text { Formative assessment } \\
\text { (project work, presentation, } \\
\text { speech, collaborative } \\
\text { activities) }\end{array}$ \\
\hline
\end{tabular}


In DJP model classrooms, the strengths of traditional Chinese classroom teaching are retained. Teachers provide students with challenging and carefully selected tasks in well-designed, coherent lessons. The model emphasizes teachers' guidance of students' exploration and explanation to ensure class effectiveness and efficiency. While it aims to increase students' participation and interest in learning, it also focuses on their knowledge acquisition. Some features found to be traditional and backward-such as teachers dominating in-class talk without giving students an opportunity to express their ideas, interact and collaborate; teachers asking closed questions and students giving choral responses; and teachers neglecting students' interest in learning [39,41]—were replaced with more student-centered activities (e.g., exploration, group discussions and student presentations). These activities aim to increase students' active participation in class, cultivate their interest in learning and develop their ability to express ideas, communicate and cooperate with others [43].

\section{Research Method}

\subsection{Site}

LQY is a big district in the eastern part of Chengdu city. It covers an area of 556 square kilometers and has around 870,000 people. It used to be a rural district but in the past 10 years, the introduction of car factories led to its rapid economic development. However, education cannot change as fast and dramatically as the economy. There are 21 middle schools (grades 7-9) and 5 high schools (grades 10-12) in the district. Some of the schools are at an average level while some are below average compared to schools in the whole city. This study investigated mathematics teachers in grades 7 and 8 , as the DJP model was originated in middle school math classes. In total, there are around 300 middle school math teachers. Students in grades 7 and 8 are about 13 to 14 years old and most of them come from low-income families.

The reform experiment began in 2006, in one of the poorest middle schools in LQY district. Many of the students did not understand mathematics content despite continual explanations by teachers, and some obtained high exam scores but did not have an interest in studying, cooperating and communicating. A research team formed to explore appropriate ways to ameliorate the situation developed a trial instructional model consisting of one focus, to improve students' learning; three aspects, what to learn, how to learn it and how the learning is done; and three activities, self-study, student teaching and peer commenting. After two years of experimentation, the school experienced many changes in students' achievements and learning interest. Inspired by this success, other schools began to join the reform. In 2008, the research group named this reformed model the DJP model. Since then, all schools in LQY district are required to implement the DJP model. The implementation of the model has brought about considerable changes in students' academic performance and improved the ranking of schools. The DJP model was awarded first prize in the fifth general education instruction innovation in Sichuan Province and second prize in achievements in teaching and learning at the national level.

\subsection{Overall Design of the Longitudinal Project}

This study was a longitudinal project investigating the degree of implementation of the DJP model in LQY district and the factors that influence teachers' levels of implementation. The project design had two phases.

Phase 1, which covered 2012-2013, examined the levels of implementation of the DJP model in schools in LQY district. Sixteen junior secondary teachers (5 men and 11 women) were selected from the district, with different teaching experience across schools with outstanding, moderate and low achievement. Sixty-four lessons were recorded and analyzed for the 16 participants, with four lessons for each teacher. Considering the specific features of the DJP model (e.g., student teaching and peer commenting), the level of implementation was measured by the duration of students' verbal participation in class (e.g., answering questions, presenting, participating in group discussions 
and expressing their opinions) and the quality of their participation (simple answer, explanation or exploration). A further description of the design of phase 1 can be found in [46].

Phase 2, which covered 2016-2017, explored the factors influencing teachers' levels of implementation of the DJP model. Of the participants in phase 1, this study investigates six teachers, three with a high level and three with a low level of DJP implementation. Details of the design of phase 2 are presented in the following section.

\subsection{Research Design of Phase 2}

\subsubsection{Participants}

Based on the results of phase 1 (which have been published), this study used duration and quality of student participation as criteria to categorize teachers' DJP implementation into high and low levels, as shown in Table 2.

Table 2. Definition of levels of DJP implementation.

\begin{tabular}{cll}
\hline Level & Duration of Student Participation & Quality of Student Participation \\
\hline High & $\begin{array}{l}\text { Among the } 80 \text { min of class time (two consecutive lessons), } \\
\text { the duration of student participation is more than } 30 \mathrm{~min}\end{array}$ & and \\
\hline Low & $\begin{array}{l}\text { Among the } 80 \text { min of class time (two consecutive lessons), } \\
\text { the duration of student participation is less than } 30 \mathrm{~min}\end{array}$ & $\begin{array}{l}\text { or } \\
\text { teaching is more than } 15 \text { min }\end{array}$ \\
\hline
\end{tabular}

Phase 2, which covered 2016-2017, explores factors that influence teachers' levels of DJP implementation. Six teachers were selected, three with a high level of implementation and three with a low level (see those marked with * in Figure 3). Phase 1 of the project found that there was no significant correlation between years of teaching experience and level of DJP implementation. Thus, among the three teachers at each level, we tried to select those with varied teaching experience. In addition, in each group of teachers we included classes of students at different levels in terms of performance in mathematics, as we did not find a strong connection between student levels and levels of DJP implementation in previous studies. As explained in Section 4.1, DJP actually originated and was implemented successfully in one of the poorest schools in the district. Therefore, we aimed to explore what the important factors are, if these characteristics are not the determining factors, that lead to differences in teachers' levels of DJP implementation.

Their basic information is presented in Table 3.

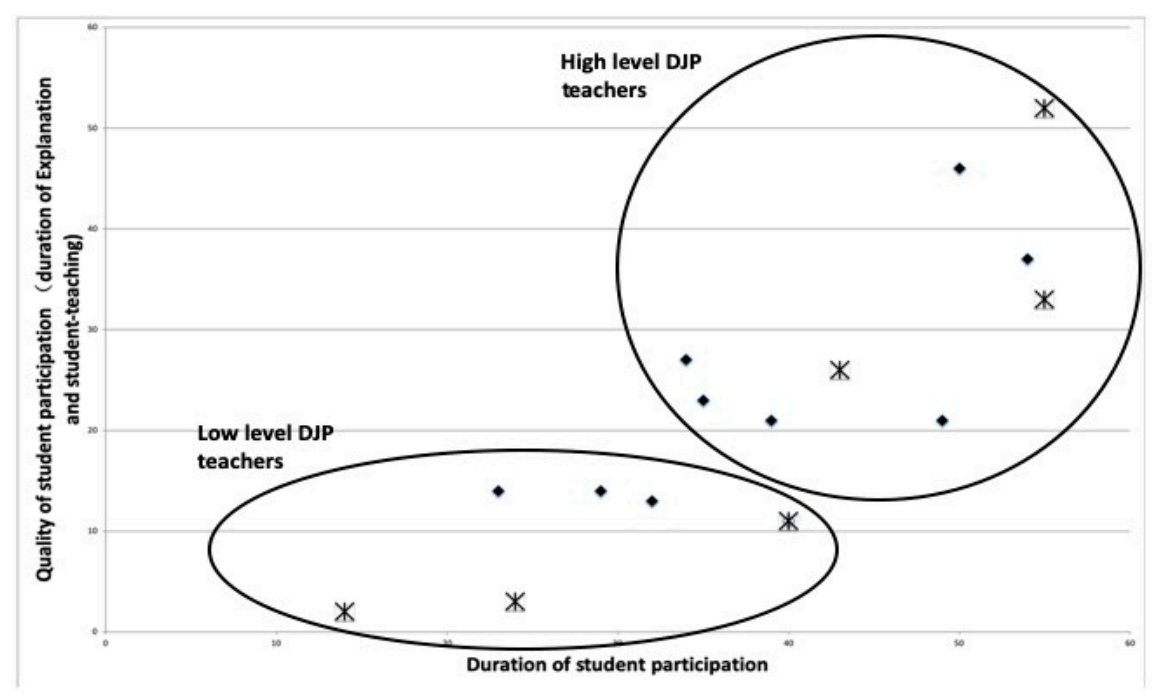

Figure 3. Levels of implementation of the 16 teachers. 
Table 3. Basic information of six teachers in the study.

\begin{tabular}{ccccc}
\hline Teacher & Gender & $\begin{array}{c}\text { Years of Teaching } \\
\text { (by 2016) }\end{array}$ & Level of Students & $\begin{array}{c}\text { Level of DJP } \\
\text { Implementation }\end{array}$ \\
\hline T1 & Female & 11 & Average & High \\
T2 & Female & 10 & Below average & High \\
T3 & Male & 19 & Average & High \\
T4 & Female & 22 & Below average & Low \\
T5 & Female & 4 & Average & Low \\
T6 & Female & 22 & Average & Low \\
\hline
\end{tabular}

\subsubsection{Data Collection}

Each of the six teachers was followed by the researcher for one week to observe their daily work and participate in their research activities if possible. Multiple data sources, including audiotaped interviews, notes from observations and videotaped lessons, were collected to have a relatively holistic description of the teachers.

Each teacher was invited for an individual interview, which lasted around $40 \mathrm{~min}$. The interview protocol was developed based on the TPB framework, which covers three dimensions: attitude towards the DJP model, subjective norms and perceived behavioral control.

The following main interview questions were posed:

(1) What do you think of the DJP model? What are the advantages and disadvantages of the DJP model? (Attitude towards the behavior);

(2) What are the expectations of your school leaders, colleagues and students in terms of your DJP implementation? What are your attitudes towards their expectations? (Subjective norms);

(3) What are the helpful factors and difficulties in terms of DJP implementation? (Perceived behavior control).

Probing questions were asked based on the responses. Opportunities were offered for the teachers to express concerns beyond the three dimensions through questions such as "What else do you think influences your implementation of the DJP model?"

\subsubsection{Data Analysis}

Based on the TPB framework, we developed the analytical framework shown in Figure 4.

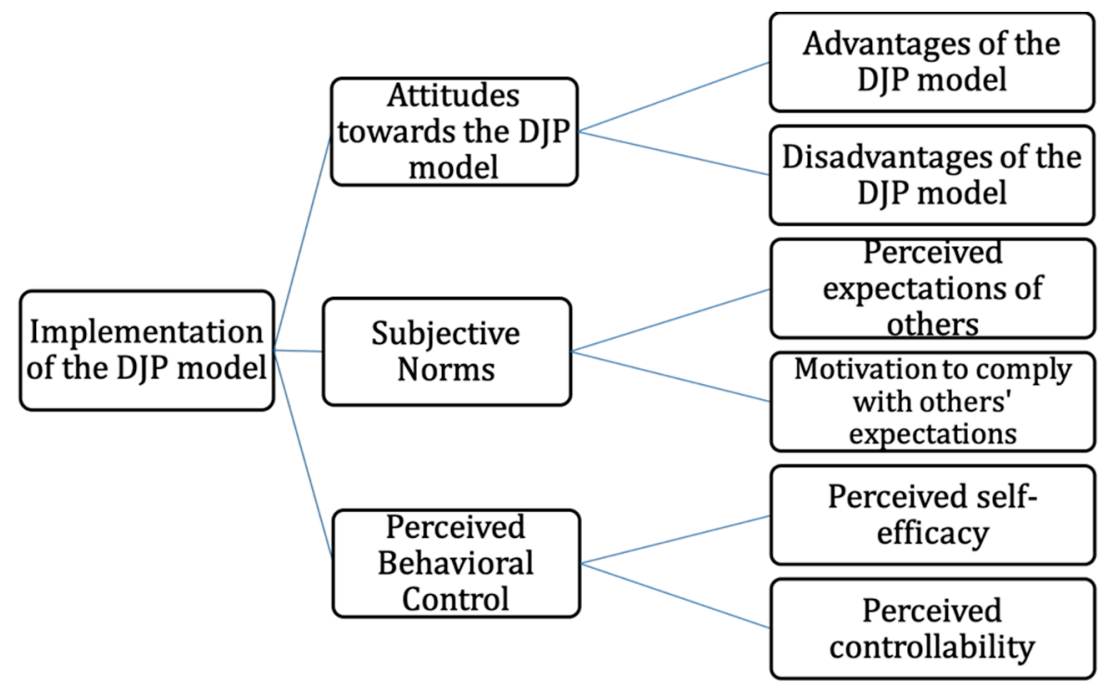

Figure 4. Analytic framework for this study. 
Adopting this data analysis framework, the analysis process was conducted as follows. First, the interviews were transcribed. The analysis was conducted on the original Chinese texts. Second, key phrases were extracted from the text and categorized using the analytical framework. Two researchers, both authors of this paper, coded two teachers' interviews together and differences were addressed through extensive discussion. Then one researcher finished the remaining part. Finally, two researchers reviewed and discussed the process of data analysis again until both agreed on the coding results. Although coding was conducted on interview transcripts, other data sources, including notes from observations and classroom observations, were also taken into consideration to have a better understanding of teachers' responses. An example of this process is presented in Figure 5.

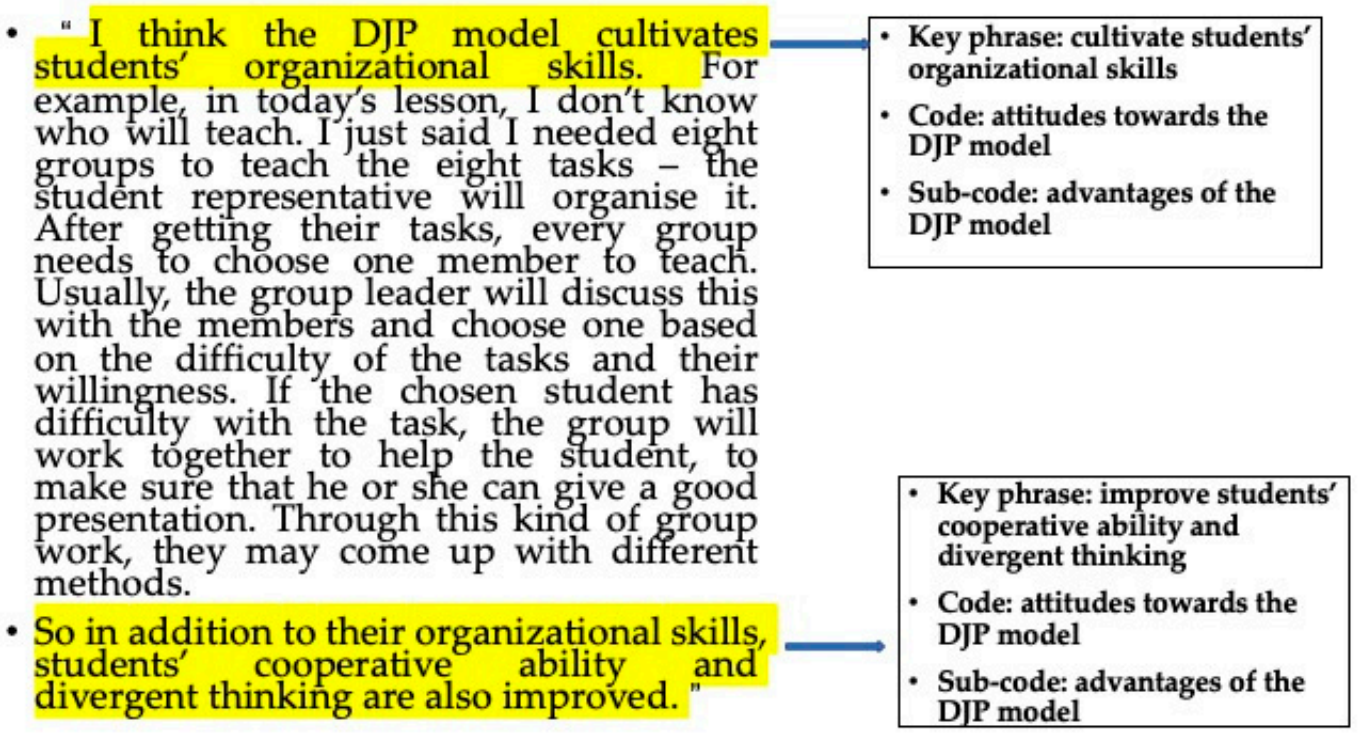

Figure 5. Example of coding procedure. Note: The content of this example was translated into English for the reader's information. The actual analysis was conducted on the original Chinese text.

Third, additional dimensions were added if there were phrases that could not be categorized in the initial framework. Phrases extracted from the interviews are summarized in Table 4 for comparison.

Table 4. Six teachers' major concerns when implementing the DJP model.

\begin{tabular}{|c|c|c|c|}
\hline & $\mathrm{T} 1, \mathrm{~T} 2, \mathrm{~T} 3$ & T4, T5, T6 & $\begin{array}{l}\text { Major Concerns } \\
\text { (Factors) }\end{array}$ \\
\hline $\begin{array}{l}\text { Attitude: advantages and } \\
\text { disadvantages of the model }\end{array}$ & 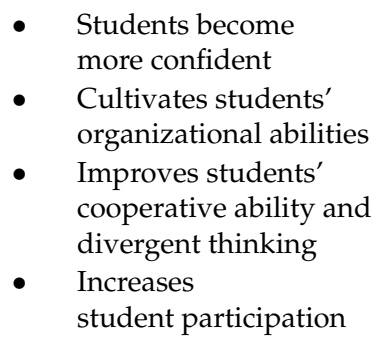 & $\begin{array}{l}\text { - } \\
\text { pot efficient or } \\
\text { large class size and } \\
\text { heavy workload } \\
\text { Only benefits } \\
\text { good students } \\
\text { Traditional teaching } \\
\text { is better than the } \\
\text { DJP model }\end{array}$ & 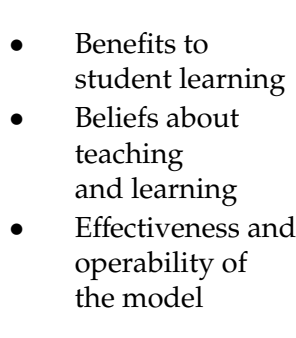 \\
\hline
\end{tabular}


Table 4. Cont.

\begin{tabular}{|c|c|c|c|}
\hline & $\mathrm{T} 1, \mathrm{~T} 2, \mathrm{~T} 3$ & T4, T5, T6 & $\begin{array}{l}\text { Major Concerns } \\
\text { (Factors) }\end{array}$ \\
\hline $\begin{array}{l}\text { Subjective norms: perceived } \\
\text { expectations of school } \\
\text { leaders and students, and } \\
\text { motivation to comply }\end{array}$ & $\begin{array}{l}\text { - Schools embrace } \\
\text { the reform } \\
\text { School leaders are } \\
\text { supportive in } \\
\text { promoting the model } \\
\text { - } \quad \text { Students like it and } \\
\text { benefit from it }\end{array}$ & 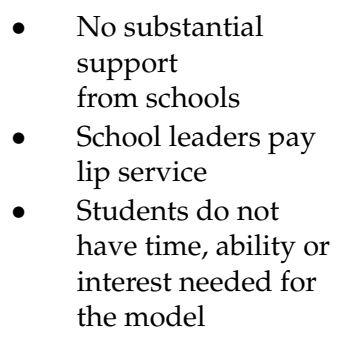 & $\begin{array}{ll}\text { - } & \text { School culture } \\
\text { - } & \text { Expectations of } \\
\text { school leaders } \\
\text { - } & \text { Attitudes and } \\
\text { abilities of students }\end{array}$ \\
\hline $\begin{array}{l}\text { Perceived behavioral control: } \\
\text { perceived self-efficacy and } \\
\text { controllability }\end{array}$ & $\begin{array}{l}\text { - Students "waste" } \\
\text { class time } \\
\text { - Challenges are } \\
\text { under control }\end{array}$ & $\begin{array}{ll}\text { - } & \text { Too much work } \\
\text { - } & \text { Limited time } \\
\text { - } & \text { Not operationalized } \\
\text { - } & \text { Pressure } \\
& \text { from exams } \\
\text { - } & \text { Too idealistic }\end{array}$ & $\begin{array}{l}\text { Effectiveness and } \\
\text { operability of } \\
\text { the model } \\
\text { - } \quad \text { Exams } \\
\text { - Workload and } \\
\text { limited time }\end{array}$ \\
\hline $\begin{array}{l}\text { Additional dimension: } \\
\text { interpretation of the model }\end{array}$ & $\begin{array}{l}\text { - Students play a central } \\
\text { role, and teachers } \\
\text { are facilitators } \\
\text { DJP model is an } \\
\text { instructional } \\
\text { philosophy, rather than } \\
\text { a fixed procedure that } \\
\text { must be followed }\end{array}$ & $\begin{array}{l}\text { Mathematics is } \\
\text { professional and } \\
\text { accurate and thus } \\
\text { should be taught } \\
\text { by teachers } \\
\text { It is impossible to } \\
\text { follow the } \\
\text { procedures of the } \\
\text { model as teaching } \\
\text { is a flexible activity }\end{array}$ & $\begin{array}{l}\text { - Teacher's } \\
\text { understanding of } \\
\text { the nature of } \\
\text { activities in } \\
\text { the model }\end{array}$ \\
\hline
\end{tabular}

\section{Results}

In this section, the findings of phase 1 are summarized (an expanded report on phase 1 can be found in [47]) to determine a basis for the discussion of factors influencing teachers' DJP implementation. The findings of phase 2, focusing on the factors, are then reported in detail.

\subsection{Phase 1: Levels of Implementation of DJP Model}

Figure 6 presents the 16 teachers' levels of implementation of the DJP model in 2012 and 2013 according to the duration and quality of student participation in 64 lessons. A majority of the teachers had made an effort to facilitate student participation. The average student participation time was $39 \mathrm{~min}$ in 2012 and $37 \mathrm{~min}$ in 2013 (out of a total of $80 \mathrm{~min}$ ). For most of the teachers, the students participated in their classrooms for more than $30 \mathrm{~min}$. When looking at the depth of student participation, we can see that explanation constituted the highest proportion, which means that students always gave reasons for their answers. From the videos, we observed that most teachers encouraged and guided students to explain their answers rather than just accepting simple answers. Overall, we can say that the average level of implementation of the DJP model increased a little in 2013 compared to 2012 (we see less simple answering and more student teaching). Even though the level decreased a little for seven teachers over the two-year period in terms of duration of student participation, in most cases it was because of a decrease in simple answering (low-quality student participation) with a slight increase in student teaching (high-quality student participation). In addition, the duration of student participation ranged from $11 \mathrm{~min}$ to $70 \mathrm{~min}$. 


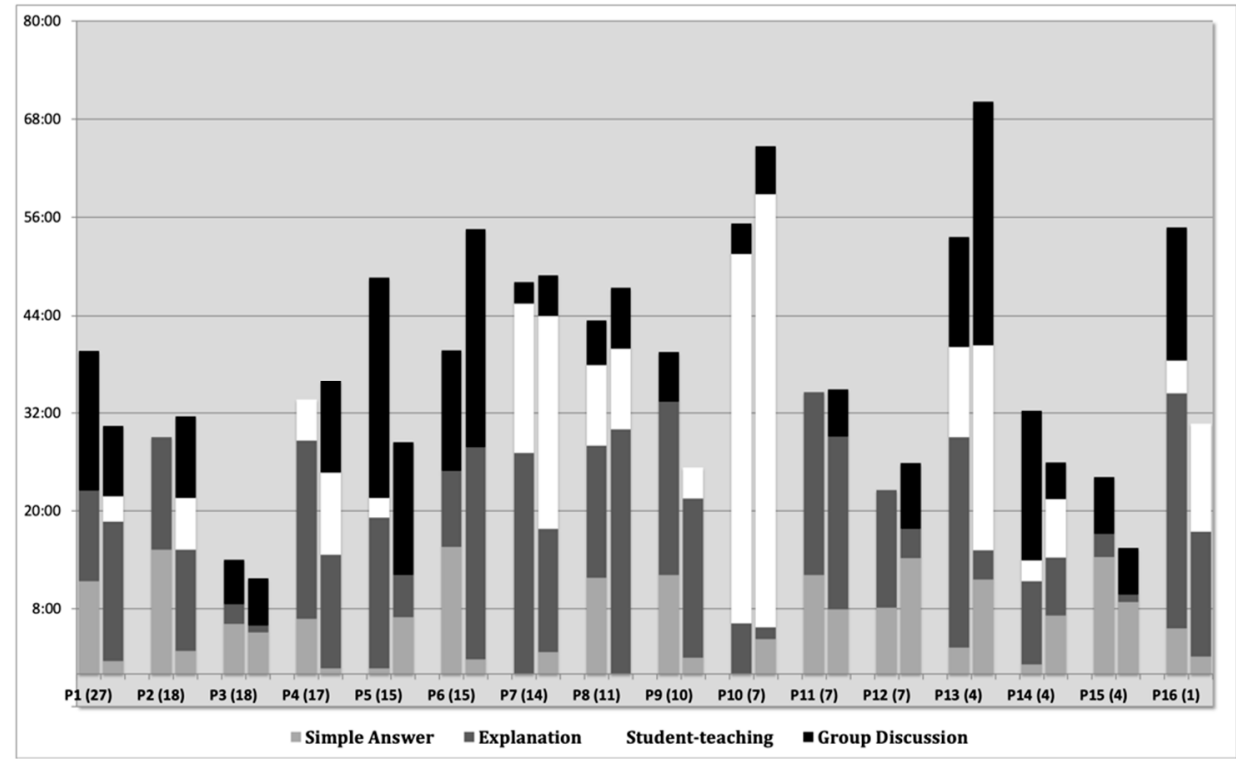

Figure 6. Levels of DJP implementation by 16 teachers; data from 2012 and 2013 (adapted from [47]). Note: One 80-min lesson was analyzed for each teacher in 2012 and 2013. Numbers in brackets represent years of teaching experience. Every teacher has two bars: results from 2012 on the left, and results from 2013 on the right.

\subsection{Phase 2: Factors Influencing Teachers' Levels of Implementation of DJP Model}

This section reports our findings on the factors influencing levels of implementation of the DJP model. The results of the data analysis are presented in Table 4. Section 5.2.1 reports the six teachers' attitudes towards the DJP model, including their perceptions of its advantages and disadvantages. Section 5.2.2 reports the teachers' subjective norms in terms of the expectations they perceived from school leaders and students, and their motivation to meet these expectations. Section 5.2.3 reports the participants' perceived control over the implementation of the DJP model from the perspective of their perceived self-efficacy and controllability. Section 5.2.4 reports an additional factor that is not reflected in the TPB framework: teachers' understanding of the DJP model.

\subsubsection{Attitudes}

The six teachers were asked to describe the advantages and disadvantages of the DJP model to demonstrate their attitude. The results show that T1, T2 and T3, who had a high level of DJP implementation, had a favorable attitude towards the model, while T4, T5 and T6, who had a low level of implementation, had an unfavorable attitude.

T1 said that after implementing the model, her students became more confident, and their organizational and cooperative abilities and divergent thinking improved. She stated:

I think the DJP model cultivates students' organizational skills. After getting the tasks, every group needs to choose one member to teach. Usually, the group leader will discuss this with the members and choose one based on the difficulty of the tasks and their willingness. If the chosen student has difficulty with the task, the group will work together to help the student, to make sure that he or she can give a good presentation. Through this kind of group work, they may come up with different methods. So, in addition to organizational skills, students' cooperative ability and divergent thinking are also improved. (T1)

T2 shared, "I am always exploring ways to increase students' participation in class. When I learnt about the DJP model, I was so excited. I know I am right. So, I fully trust the DJP model." T3 said, "After using the DJP model, students enjoy the lesson more and become more confident. I feel my job is meaningful." 
Unlike T1, T2 and T3, T4, T5 and T6 had an unfavorable attitude towards the DJP model. T4 mentioned she was used to traditional ways of instruction, and so resisted the model when she first learned about it. She thought that time given to students to teach was wasted. In the implementation, she found that students could not express what she wanted to express, or the important parts of solutions. She thought the model's ideas were right, but still rather difficult to implement. T5 shared a similar struggle because of the conflict between her traditional beliefs and the DJP philosophies.

T6 thought the traditional way of teaching was better than the DJP model in the Chinese context and that the virtues of traditional education should be maintained. She said:

We know that foreign countries even import mathematics teachers from China because they think our mathematics education is good. Our students perform very well, which is not because of the DJP model, right? It is because of our traditional teaching! I think we need to keep the virtues of our education. For our country, because of our tradition and big classes, it is impossible for one reform or one model to change the system. I still think traditional education is good.

From the teachers' interviews, we can see that T1, T2 and T3's favorable attitude towards the DJP model was mainly due to the positive changes they saw in their students after implementing it; for instance, students became more confident, their organizational skills were cultivated and they developed divergent thinking skills. T4, T5 and T6 thought the DJP model was not practical enough due to large class size and heavy workload. T6 especially spoke highly of traditional Chinese education.

\subsubsection{Subjective Norms}

TPB holds that individuals' behaviors are influenced by the people around them, especially important others. However, individuals may or may not comply with these important others' expectations. In this study, the participants' perceptions of expectations from school leaders and students were examined.

\section{School leaders}

T1, T2 and T3 said their schools embraced reforms and encouraged new ideas, and school leaders supported their implementation of the DJP model by providing equipment such as small blackboards for students to prepare their work and IT equipment to play slides and videos, as well as providing regular training programs both inside and outside the school. They were often rewarded for their successful implementation, thus willing to comply with expectations. On their campuses, there were many boards to display students' work, activities, teams, etc.

$\mathrm{T} 4, \mathrm{~T} 5$ and $\mathrm{T} 6$ also felt that their schools encouraged them to carry out lessons following the DJP model; however, there was almost no substantial support. Teachers said that school leaders were paying lip service. Their work performance was still determined by students' test scores. They thought teachers should make their own decisions instead of just following what school leaders said. For instance, T6 said, "The school is supporting us to implement the DJP model. But you know, we are not robots. We cannot do exactly the same thing."

\section{Students}

T1, T2 and T3 shared that students gave them strong motivation to implement the DJP model, as they saw positive changes in students following its implementation. T2 expressed that students' abilities were improved after implementing the model, thus she embraced it and would not give up on it, despite facing many challenges. T3 like the DJP model because the relationship between teacher and students become more harmonious, and he gradually realized that short-term achievements were not the final goal of education. 
However, the other three teachers mentioned that students' lack of motivation and ability was a major challenge for them to implement the DJP model. T4 shared:

I observed some DJP lessons, I think it is very good. But you know, their students are high-ability students, not like our students. I think our students are too poor to do the DJP. They can just present what they had, it is very difficult to train them to explain the ideas clearly and act as a teacher. It is too difficult. (T4)

T6 mentioned that the DJP model cannot satisfy every student. She thought that only good students could be trained to teach, so the model could only benefit good students. She said:

The benefits of the DJP model depend on different students. Good students know how to solve the problem, and they can teach. Poor students, when they speak, most of their thoughts are wrong, so they are afraid that other students will laugh at them. So not all students can be trained as "little teachers." Also, some students are not good at explaining their ideas, so other students just do not want to listen.

The subjective norms, expectations of school leaders and attitudes and abilities of students influenced the teachers' DJP implementation. However, it seems that students had the greatest influence, as the teachers cared more about their abilities, attitudes and performance when implementing the model.

\subsubsection{Perceived Behavioral Control}

Another dimension of TPB is teachers' perceptions of their abilities and the resources to perform behaviors. In this section, the teachers' perceived difficulties in carrying out the DJP model and their confidence to overcome these difficulties (perceived self-efficacy) are discussed.

One challenge T2 and T3 mentioned was teachers' attitudes towards time "wasted" by students and their perseverance in DJP implementation. Also, they held a different opinion from most teachers. For instance, T2 said:

The biggest problem for some teachers is that they think students teach very slowly; the time is wasted and the other students learn nothing. My opinion is different. You finish all the content, but that does not mean the students have command of all the content and their abilities have improved. What I teach is not just knowledge, but also ability. For example, self-study is very important in the DJP model. After they have this ability, they can learn by themselves. (T2)

T4 and T5 thought the DJP model was inefficient and impractical because students did not have the time to prepare well for class. Teachers were also under pressure to cover the learning content. For instance, T5 said:

If you want students to explain clearly, they need to put a lot of effort into it. Now students have so many classes-five classes in the morning, five classes in the afternoon, classes at noon and in the evening. How can students find time to think about problems deeply and prepare for teaching? I think this thing [the DJP model] is too idealistic. (T5)

T6 also mentioned the pressure of exams and the challenge of covering all the content required. She said:

It is impossible to train every student into a "little teacher." It is not realistic. You have so many teaching tasks, and you need to care about teaching progress and worry about students' performance in exams. So, you need to deal with it flexibly. I will not use this model in every lesson. (T6) 
From the TPB perspective, the results reveal that the teachers all faced obstacles when implementing the DJP model. These challenges included time, exams and heavy workload. However, some dealt with these difficulties in a positive way. They tried to find solutions to these problems. Considering these contextual obstacles, T4, T5 and T6 thought that the DJP model was impractical and idealistic.

\subsubsection{An additional Dimension: Teachers' Understanding of the DJP Model}

In addition to the factors related to the three aspects of TPB-attitudes, subjective norms and perceived behavioral control-another important factor emerged from the data: the teachers' understanding of the nature of activities in the DJP model.

The interviews show that the teachers had different interpretations of the model. Unfavorable attitudes or superficial reform implementation could have stemmed from their misunderstanding of the reform ideas.

In the DJP model, the roles of teachers and students are different from those in traditional classrooms. Students play a more central role and teachers are expected to be facilitators, organizers and guides.

T1 said she gave as many opportunities for students to teach as possible. She had a good understanding of the purpose of inviting students to teach. During their teaching, she encouraged students to highlight their methods and mathematical thinking. She said:

I feel that maybe I consciously cultivate students' ability to summarize the mathematics methods and think through the process of problem solving. The students in my class know the terms of these methods and can explain how and why to use them, while in other teachers' classes, their students know how to solve the problems but are not aware of the methods they are using. I think this may be because I always require them to summarize their methods in the problem-solving process.

T2 emphasized the teacher's important role in DJP lessons as a facilitator to clarify, highlight and supplement the students' explanations. She commented:

Sometimes, students cannot clearly explain the methods, the variations of problems and the connection of the new knowledge with previous knowledge. In this case, as a teacher, I should make it clear. This high level of teaching should be provided by the teacher to supplement students' explanation.

Although the DJP model has three elements and several procedures, it should not be regarded as a set of fixed procedures to follow. T3 agreed, stating, "I don't think that teachers should do it step by step. As long as students are actively involved, it is a good DJP lesson."

Furthermore, we observed that T4, T5 and T6 had some misunderstanding of the DJP model, especially the purpose of and rationale for student teaching. For example, T4 thought that students could only teach simple or procedural tasks, whereas the purpose of student teaching in the DJP model is to encourage students to share their ideas and thoughts, rather than to demonstrate procedures or simply follow the teacher's procedures. T5 only asked students to display their work on the blackboard instead of inviting them to explain their answers. Furthermore, T6 mistook the DJP model as a fixed procedure, when it is actually an instructional philosophy, with suggested procedures to facilitate active learning, student engagement and students' explanations. This result echoes the arguments of Spillane, Reiser and Gomez [24] that teachers may understand reform plans differently from policymakers and thus implement them in ways that are different from expectations.

\section{Conclusions}

This study shows that teachers in the LQY district had overall high but individually varying levels of DJP implementation and explores the factors that influence implementation through a comparison of six teachers' attitudes towards the DJP model, perceptions of expectations from school leaders and 
students and perceived difficulties with implementation. This study reveals the main concerns that the six teachers had in the process of DJP implementation.

Individually, teachers who had a high level of DJP implementation focused on the advantages of the model, forming a favorable attitude towards it. However, teachers who had a low level of DJP implementation were concerned about its disadvantages, leading to an unfavorable attitude. Their beliefs about the advantages and disadvantages of implementing the model were related to their evaluations of the model's benefits for student learning and their beliefs about effective teaching and learning. In addition, different teachers may understand the model differently, leading to different ways of implementing it.

Socially, the three high-level DJP teachers felt support from their school leaders and students to follow the model, and they were willing to meet their expectations. However, the three low-level DJP teachers did not feel support from their schools and had little motivation to comply with the expectations of school leaders. They felt that students did not have strong motivation or sufficient abilities to cope with the DJP model. Thus, some teachers benefitted from their school community to improve their level of implementation, while some gradually went back to their traditional way of instruction.

In terms of their perceived difficulties in DJP implementation, they mentioned the challenges involved in enacting the model. However, high-level DJP teachers showed their confidence in overcoming these difficulties. Low-level DJP teachers mentioned factors including pressure from exams and challenges in covering instructional content in a limited time; thus, they perceived the model as too ideal. They thought these contextual barriers could not be overcome by one person or even one reform.

In addition to the three aspects of attitudes, subjective norms and perceived behavioral control, this study found a dimension that also influences teachers' implementation of the DJP model but is not included in the TPB framework: teachers' understanding of the model. The results show that teachers with a low level of DJP implementation greatly misunderstood the model.

In conclusion, this study summarizes the factors influencing teachers' implementation of the DJP model based on their concerns reflected in the three dimensions of TPB (attitudes, subjective norms and perceived behavioral control) and the additional dimension of their understanding of the model. These factors can be placed into three categories:

- Individual factors that relate to teachers' attitudes, beliefs, self-efficacy and understanding of the reform.

- Perceived social factors that relate to teachers' perceived subjective norms, including school culture, the support of school leaders and the motivation and attitudes of students.

- Perceived contextual factors that relate to teachers' perceived behavioral control, including the effectiveness and operability of the DJP model, and pressure from exams, heavy workload and time limits.

\section{Discussion}

This study has both theoretical and practical contributions. Theoretically, this study refines the TPB framework to improve its validity in explaining teachers' behaviors in reform contexts. Practically, drawing on the experience of the DJP model, this study provides suggestions on how to get teachers to implement new teaching methodologies continuously, which is the concern of reform implementation in many other contexts.

\subsection{Theoretical Attribute of the TPB Framework}

This study shows that TPB is a suitable framework for examining factors that influence teachers' implementation of reform. However, teachers' understanding of reform ideas, which is an important factor, is not explicitly reflected in the TPB framework. This observation is supported by other 
studies [19,36]. For example, Underwood [19] examined teachers' beliefs and intentions regarding instruction under national curriculum reform from the TPB perspective, arguing that Japanese teachers' negative attitudes towards reform-oriented teaching were due to their misperception of the proposed reform ideas and exam requirements. Remillard [48] also pointed out that curriculum reform was never a straightforward process of executing prescriptions; rather, teachers' practices in carrying out reform were products of a sense-making process between the teachers and the ideas. Hence, this study contributes to TPB theory by offering empirical support for the feasibility of adding teachers' understanding of reform as an additional dimension to enhance its explanation of teachers' innovative behaviors in the context of curriculum reform.

\subsection{How to Get Teachers to Implement Reform Ideas Sustainably}

Among the various factors, this study highlights several aspects that are important for getting teachers to implement reform ideas continuously, thus ensuring the sustainability of reform implementation.

First, teachers' pedagogical beliefs should align with reform ideas. Belief is one of the most valuable psychological constructs for teaching [49], and can influence teachers' pedagogical decisions, instructional practices, selection of materials and professional development. When teachers' beliefs align with reform proposals, it is more likely that they will have positive attitudes and strong intention regarding implementation. On the other hand, when their beliefs and the reform philosophy do not align, teachers tend to have a negative attitude and reject the reform.

Second, teachers need to understand not only how to facilitate proposed reform activities but also the rationale and value behind these activities. Understanding reform ideas is an important but often overlooked factor. Many policymakers blame teachers for their unwillingness to change their way of teaching, overlooking the possibility that teachers do not fully understand or even misunderstand the reform proposals. In this study, we found that T4, T5 and T6 only knew the procedures of the DJP model but did not understand why these procedures are important. The results suggest that when implementing reform ideas that are usually abstract and hard to understand, it is critical to examine whether teachers understand those ideas and the philosophies.

Third, school culture and support from school leaders are necessary to ensure the sustainability of teachers' implementation. Whitaker [50] highlights that a key factor in leading change successfully is "the capacity to give deliberate attention to the building and development of an organizational culture conducive to collaboration, participation and change" (p. 102). Thus, school leaders are important in implementing reforms. With their support, teachers can have continual motivation and resources to support the implementation. This study shows that the three teachers with a high level of DJP implementation had a school culture that embraced reform and support from principals. However, the three teachers with a low level of DJP implementation had a relatively conventional school culture that did not welcome new ideas, so school leaders did not provide useful support.

Lastly, teachers should value students' long-term development. Teachers mentioned that high-stake exams hinder their motivation to implement reform ideas. However, this study found that pressure from exams is not a determining factor, as under such pressure, T1, T2 and T3 still spoke highly of the reform model. We argue that their opinions on exams actually reflect their values of the goal of education. T1, T2 and T3 tended to value students' long-term development, such as organizational skills, communication skills and interest in mathematics, while T4, T5 and T6 tended to care more about students' short-term performance, for instance, test scores. In addition, the high-level DJP teachers did not perceive students' long-term development and performance on exams as contradictory. They thought students' development of abilities would enhance their learning of knowledge and academic performance, thus high-stake exams in China do not become barriers for them. 


\subsection{Implication for Teachers' Professional Development Programs}

The findings of this study can shed light on professional development programs for teachers in China and in similar contexts. Professional development programs should consider teachers' attitudes towards a reform and their interpretations of its ideas. Policymakers and teacher trainers should be aware that teachers may misinterpret reform ideas, leading to unfavorable attitudes and superficial implementation. As teachers' main concern is evaluating a reform's value, it is necessary to present evidence of the benefits to student learning while promoting it. Students' attitudes and expectations in fact profoundly influence teachers' acceptance and implementation of reforms. Thus, strategies for motivating students and catering to their diversity are essential for effective professional teacher programs. Another major concern is the environment. Continuous provision of an environment and programs that support teacher collaboration, reflection and sharing is important.

\subsection{Limitation}

A limitation of this study is the sample size, as only six teachers were examined. Being aware of this limitation, this study tried to select teachers that were not the best or worst, but also in the middle, thus to some extent could represent a group of teachers. In addition, researchers followed the teachers for one week, to observe their daily work and take many notes, which helped to give as detailed description of each teacher as possible. Lastly, the main purpose of examining the six teachers was not to generalize the findings to the whole district or all of China, but to learn from the successful experience of the DJP model and teachers who implemented the model better than others. We believe, in this aspect, we have achieved our purpose.

Author Contributions: Conceptualization, W.Z., I.A.C.M., and Y.C.; Methodology, W.Z., I.A.C.M.; Formal Analysis, W.Z., I.A.C.M.; Investigation, W.Z., I.A.C.M., and Y.C.; Resources, W.Z., I.A.C.M., and Y.C.; Writing-Original Draft Preparation, W.Z.; Writing-Review \& Editing, W.Z., I.A.C.M., and Y.C.; Supervision, I.A.C.M., and Y.C.; Project Administration, Y.C.; Funding Acquisition, Y.C. All authors have read and agreed to the published version of the manuscript.

Funding: This research was funded by China National Education Sciences Grant (2018): Middle School Students' Cognitive interaction and Social interaction in Collaborative Problem Solving (Grant No. BHA180157).

Conflicts of Interest: The authors declare no conflict of interest.

\section{Appendix A. Appendix: Examples from DJP Classrooms}

\section{Example 1:}

(This lesson is about the formula: $(a+b)(a-b)=a^{2}-b^{2}$. One student is standing in front of the class to explain the nature of $a$ and $b$.)

Student 1: From example 1 and example 2, we can see in this formula that $\mathrm{a}$ and $\mathrm{b}$ can be numbers, monomials and polynomials. The first example is $(2009+1)(2009-1)$, in which a and $b$ are numbers; the second example is $(m+n)(m-n)$ in which $a$ and $b$ are monomials; the third example is $[(x-m)-(n+c)][(x-m)+(n-c)]$, in which a and $b$ are polynomials. When we use this formula, we need to make sure it is a product, and it has something like a + $\mathrm{b}$ and something like $\mathrm{a}-\mathrm{b}$. Also, be careful to put the $\mathrm{a}$ first and the $\mathrm{b}$ second, which makes the answer $a^{2}-b^{2}$.

(The whole class gives her a round of applause.)

Teacher: Very good! Does anyone have anything to add?

Student 2: In this formula, a and $\mathrm{b}$ cannot be 0 , otherwise, this equation will be meaningless.

Teacher: Meaningless? What about $(0+0)(0-0)=02-02$ ?

Student 3: From this example, we can see that $\mathrm{a}$ and $\mathrm{b}$ can be any number including 0 . 


\section{Example 2:}

(This lesson is about the property of similar triangles. One student is standing in front of the class to facilitate a lesson on how to find corresponding sides.)

Student A: We have learned the property of similar triangles, which says corresponding angles are congruent and corresponding sides are proportional. Now let us discuss a special situation. If we have two similar triangles: $\triangle \mathrm{ABC}$ and $\triangle \mathrm{ADE}$, can you find their corresponding sides? I will find a student to answer this question. Student $B$ ?

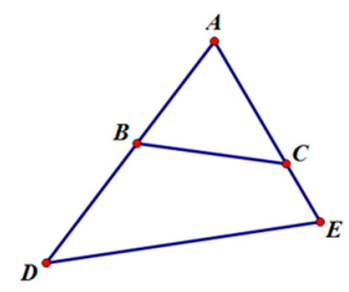

Student B: $\frac{A B}{A D}=\frac{A C}{A E}$

Student A: OK, sit down please. (To the whole class) Do you think his answer is correct?

Student C: His answer is not correct. If $\frac{A B}{A D}=\frac{A C}{A E}$, then we have $B C$ parallel to DE. We can see from the figure that $\mathrm{BC}$ is not parallel to $\mathrm{DE}$. So, the correct answer is $\frac{A B}{A E}=\frac{A C}{A D}$, then we have $\triangle \mathrm{ABC}$ is similar to $\triangle \mathrm{AED}$.

Student A: OK, very good. So, we can see from this example that sometimes the corresponding sides are not obvious. Then can someone talk about the methods we often use to find the corresponding sides in similar triangles? Let us discuss for a while.

(Several minutes later)

Student A: Can you explain some ways to find the corresponding sides?

Student $\mathrm{D}$ : We can find the corresponding sides from the question, for example if $\triangle \mathrm{ABC}$ is similar to $\triangle \mathrm{AED}$, we can tell from the order of the letters.

Student A: Yes, very good. Any other opinion?

Student E: I have two ways. One is observation. How to observe? Well, we know that $\triangle \mathrm{ABC}$ and $\triangle \mathrm{AED}$ are similar triangles. We can see from the figure that side $A B$ is the longer side of $\triangle A B C$, so it should be in proportion to the longer side of $\triangle \mathrm{AED}$. Similarly, the shorter side should be in proportion to the other shorter one. However, observation is not always right. Then I have another way, in $\triangle \mathrm{ABC}$ and $\triangle \mathrm{AED}$, if $\mathrm{BC}$ is parallel to $\mathrm{DE}$, then we have $\frac{A B}{A E}=\frac{A C}{A D}$, and we can see from the figure that obviously $\mathrm{BC}$ is not parallel to $\mathrm{DE}$, that is to say, $\angle \mathrm{ABC}$ is unequal to $\angle \mathrm{ADE}$, so they are not corresponding angles. $\angle A B C$ and $\angle A E D$ should be corresponding angles. If we found the corresponding angles, we can find the corresponding sides. Student A: Great, very good! Does everybody understand? In the future we can use these methods to find the corresponding sides in similar triangles.

In a DJP model class, these kinds of student teaching activities are very common. After receiving their tasks from the teacher, students will discuss them in groups, and then choose one student to go to the front and explain their thoughts to the whole class. From the example, we can see that during the sharing process, students not only explain the solutions but also highlight the key points of the problem-solving process. After the student's teaching, other students give supplementary information, which seldom happens in traditional Chinese classrooms.

\section{References}

1. Li, Y.; Lappan, G. Mathematics Curriculum in School Education; Springer: New York, NY, USA, 2014.

2. Schoenfeld, A.H. Reflections on curriculum change. In Mathematics Curriculum in School of Education; Li, Y., Lappan, G., Eds.; Springer: New York, NY, USA, 2014; pp. 49-72.

3. Buchs, C.; Filippou, D.; Pulfrey, C.; Volpé, Y. Challenges for cooperative learning implementation: Reports from elementary school teachers. J. Educ. Teach. 2017, 43, 296-306. [CrossRef] 
4. Castro-Villarreal, F.; Rodriguez, B.J.; Moore, S. Teachers' perceptions and attitudes about Response to Intervention (RTI) in their schools: A qualitative analysis. Teach. Teach. Educ. 2014, 40, 104-112. [CrossRef]

5. Fullan, M. The New Meaning of Educational Change, 3rd ed.; Teachers College Press: New York, NY, USA, 2001.

6. Wyss, C.; Kocher, M.; Baer, M. The dilemma of dealing with persistent teaching traditions: Findings of a video study. J. Educ. Teach. 2017, 43, 191-205. [CrossRef]

7. Maass, K.; Cobb, P.; Krainer, K.; Potari, D. Different ways to implement innovative teaching approaches at scale. Educ. Stud. Math. 2019, 102, 303-318. [CrossRef]

8. Zhou, J. Teacher education changes in China: 1974-2014. J. Educ. Teach. 2014, 40, 507-523. [CrossRef]

9. Ministry of Education. Curriculum Standards for Mathematics Curriculum of Nine-Year Compulsory Education (Experimental Version); Beijing Normal University Press: Beijing, China, 2001.

10. Li, Q.; Ni, Y. Impact of curriculum reform: Evidence of change in classroom practice in mainland China. Int. J. Educ. Res. 2011, 50, 71-86. [CrossRef]

11. Ministry of Education. Curriculum Standards for Mathematics Curriculum of Nine-Year Compulsory Education; Beijing Normal University Press: Beijing, China, 2011.

12. Yin, H. Implementing the national curriculum reform in China: A review of the decade. Front. Educ. China 2013, 8, 331-359. [CrossRef]

13. Liu, J.; Li, Y. Mathematics curriculum reform in the Chinese mainland: Changes and challenges. In Reforms and Issues in School Mathematics in East Asia: Sharing and Understanding Mathematics Education Policies and Practices; Leung, F.K.S., Li, Y., Eds.; Sense Publishers: Rotterdam, Boston, USA, 2010; pp. 9-31.

14. Ni, Y.; Li, Q.; Li, X.; Zou, J. China's new millennium curriculum reform in mathematics and its impact on classroom teaching and learning. Impact Transform. Educ. Policy China 2011, 15, 99-124.

15. He, G.F.; Gao, X. Analysis on the difference between the teaching concept and the teaching behavior of mathematics teachers in junior middle schoolbased on video analysis of 15 mathematics lessons in middle school. J. Math. Educ. 2013, 22, 24-27. (In Chinese)

16. Li, F. Standards-based instruction: Status, reflection and strategy. Curric. Teach. Mater. Method 2012, 32, 9-14. (In Chinese)

17. Ma, Y. The implementation process, characteristics analysis and promotion strategy of the curriculum reform of basic education. Curric. Teach. Mater. Method 2019, 29, 3-9. (In Chinese)

18. Wang, F.; Wang, X. How students learn knowledge from classroom interaction. Math. Educ. China 2013, 11, 3-6. (In Chinese) [CrossRef]

19. Underwood, P.R. Teacher beliefs and intentions regarding the instruction of English grammar under national curriculum reforms: A Theory of Planned Behaviour perspective. Teach. Teach. Educ. 2012, 28, 911-925. [CrossRef]

20. Alhendal, D.; Marshman, M.; Grootenboer, P. Kuwaiti science teachers' beliefs and intentions regarding the use of inquiry-based instruction. Int. J. Sci. Math. Educ. 2016, 14, 1455-1473. [CrossRef]

21. Bourgonjon, J.; De Grove, F.; De Smet, C.; Van Looy, J.; Soetaert, R.; Valcke, M. Acceptance of game-based learning by secondary school teachers. Comput. Educ. 2013, 67, 21-35. [CrossRef]

22. De Leeuw, A.; Valois, P.; Ajzen, I.; Schmidt, P. Using the theory of planned behavior to identify key beliefs underlying pro-environmental behavior in high-school students: Implications for educational interventions. J. Environ. Psychol. 2015, 42, 128-138. [CrossRef]

23. MacFarlane, K.; Woolfson, L.M. Teacher attitudes and behavior toward the inclusion of children with social, emotional and behavioral difficulties in mainstream schools: An application of the theory of planned behavior. Teach. Teach. Educ. 2013, 29, 46-52. [CrossRef]

24. Cloud, J. The Essential Elements of Education for Sustainability (EFS): Editorial Introduction from the Guest Editor. 2014. Available online: www.susted.com/wordpress/content/the-essential-elements-of-educationfor-sustainability-efs_2014_05/ (accessed on 2 December 2019).

25. Spillane, J.P.; Reiser, B.J.; Gomez, L.M. Policy implementation and cognition. In New Directions in Education Policy Implementation; Honig, M.I., Ed.; State University of New York Press: Albany, NY, USA, 2006; pp. 47-64.

26. Buabeng-Andoh, C. Factors influencing teachers' adoption and integration of information and communication technology into teaching: A review of the literature. Int. J. Educ. Dev. Using Inf. Commun. Technol. 2012, $8,136-155$.

27. Thurlings, M.; Evers, A.T.; Vermeulen, M. Toward a Model of Explaining Teachers' Innovative Behavior A Literature Review. Rev. Educ. Res. 2015, 85, 431-471. [CrossRef] 
28. Spillane, J.P.; Reiser, B.J.; Reimer, T. Policy implementation and cognition: Reframing and refocusing implementation research. Rev. Educ. Res. 2012, 72, 387-431. [CrossRef]

29. Spillane, J.P.; Zeuli, J.S. Reform and teaching: Exploring patterns of practice in the context of national and state mathematics reforms. Educ. Eval. Policy Anal. 1999, 21, 1-27. [CrossRef]

30. Ajzen, I. The theory of planned behaviour: Reactions and reflections. Psychol. Health 2011, 26, 1113-1127. [CrossRef] [PubMed]

31. Ajzen, I. The theory of planned behavior. In Handbook of Theories of Scocial Psychology: Volume 1; Van Lang, P.A.M., Kruglanski, A.W., Higgins, E., Eds.; SAGE: Los Angeles, CA, USA, 2012; pp. 438-459.

32. Ajzen, I. Attitude structure and behavior. In Attitude Structure and Function; Pratkanis, A.R., Breckler, S.J., Greenwald, A.G., Eds.; Lawrence Erlbaum Associates: Mahwah, NJ, USA, 1989; pp. 241-274.

33. Ajzen, I. Perceived behavioral control, self-efficacy, locus of control, and the theory of planned behavior. J. Appl. Soc. Psychol. 2002, 32, 665-683. [CrossRef]

34. Lin, K.-Y.; Williams, P.J. Taiwanese Preservice Teachers' Science, Technology, Engineering, and Mathematics Teaching Intention. Int. J. Sci. Math. Educ. 2016, 14, 1021-1036. [CrossRef]

35. Pynoo, B.; Tondeur, J.; Van Braak, J.; Duyck, W.; Sijnave, B.; Duyck, P. Teachers' acceptance and use of an educational portal. Comput. Educ. 2012, 58, 1308-1317. [CrossRef]

36. Milner, A.R.; Sondergeld, T.A.; Demir, A.; Johnson, C.C.; Czerniak, C.M. Elementary teachers' beliefs about teaching science and classroom practice: An examination of pre/post NCLB testing in science. J. Sci. Teach. Educ. 2012, 23, 111-132. [CrossRef]

37. Sadaf, A.; Newby, T.J.; Ertmer, P.A. Exploring pre-service teachers' beliefs about using Web 2.0 technologies in K-12 classroom. Comput. Educ. 2012, 59, 937-945. [CrossRef]

38. Cai, J.; Hwang, S. Characterizing Mathematics Education in China: A perspective on Improving Student Learning. In The First Sourcebook on Asian Research in Mathematics Education: China, Korea, Singaplore, Japan, Malaysia, and India; Sriraman, B., Cai, J., Lee, K.-H., Fan, L., Shimizu, Y., Lim, C.S., Subramaniam, K., Eds.; Springer: Berlin/Heidelberg, Germany, 2015; pp. 3-25.

39. Cao, Y.; Dong, L.; Li, X. A Study of Mathematics Classroom Teaching in China: Looking at Lesson Structure, Teaching and Learning Behavior. In The 21st Century Mathematics Education in China; Cao, Y., Leung, F.K.S., Eds.; Springer: Berlin/Heidelberg, Germany, 2018; pp. 195-222.

40. Leung, F.K.S. Some characteristics of East Asian mathematics classrooms based on data from the TIMSS 1999 video study. Educ. Stud. Math. 2005, 60, 199-215. [CrossRef]

41. Mok, I.A.C. Shedding light on the East Asian learner paradox: Reconstructing student-centredness in a Shanghai classroom. Asia Pac. J. Educ. 2006, 26, 131-142.

42. Dong, L.; Clarke, D.; Cao, Y.; Wang, L.; Seah, W. Teacher Questioning Practices over a Sequence of Consecutive Lessons: A Case Study of Two Mathematics Teachers. Sustainability 2019, 11, 139. [CrossRef]

43. Wang, F. Walking between Theories and Practices: A Collection of Research on the DJP Model; Southwest Jiaotong University Press: Chengdu, China, 2019. (In Chinese)

44. Breault. Active Learning: A Growth Experience. In Experiencing Dewey: Insights for Today's Classroom; Breault, D.A., Breault, R., Eds.; Routledge: New York, NY, USA, 2014; pp. 47-51.

45. Schweisfurth, M. Learner-centred education in international perspective. J. Int. Comp. Educ. 2013, 2, 1-8. [CrossRef]

46. Tan, C. Beyond 'either-or' thinking: John Dewey and Confucius on subject matter and the learner. Pedagog. Culture Soc. 2016, 24, 55-74. [CrossRef]

47. Zhao, W.; Mok, I.A.C.; Cao, Y. Curriculum reform in china: student participation in classrooms using a reformed instructional model. Int. J. Educ. Res. 2016, 75, 88-101. [CrossRef]

48. Remillard, J.T. Examining key concepts in research on teachers' use of mathematics curricula. Rev. Educ. Res. 2005, 75, 211-246. [CrossRef]

49. Fang, Z. A review of research on teacher beliefs and practices. Educ. Res. 1996, 38, 47-65. [CrossRef]

50. Whitaker, P. Managing Change in Schools; Open University Press: Buckingham, UK, 1993.

(C) 2019 by the authors. Licensee MDPI, Basel, Switzerland. This article is an open access article distributed under the terms and conditions of the Creative Commons Attribution (CC BY) license (http://creativecommons.org/licenses/by/4.0/). 